$-1$.

ARGONNE NATIONAL LABORATORY

P. O. BOX 299

Lemont, Illinois

EDDY CURRENT TYPE DIAMETER GAUGE

FOR CORROSION MEASUREMENTS

by

William B. Doe

SFP 1954 -.:

Remote Control Engineering Division

Operated by The University of Chicago under

Contract $W-31-109-e n g-38$ 


\section{DISCLAIMER}

This report was prepared as an account of work sponsored by an agency of the United States Government. Neither the United States Government nor any agency Thereof, nor any of their employees, makes any warranty, express or implied, or assumes any legal liability or responsibility for the accuracy, completeness, or usefulness of any information, apparatus, product, or process disclosed, or represents that its use would not infringe privately owned rights. Reference herein to any specific commercial product, process, or service by trade name, trademark, manufacturer, or otherwise does not necessarily constitute or imply its endorsement, recommendation, or favoring by the United States Government or any agency thereof. The views and opinions of authors expressed herein do not necessarily state or reflect those of the United States Government or any agency thereof. 


\section{DISCLAIMER}

Portions of this document may be illegible in electronic image products. Images are produced from the best available original document. 


\title{
2 \\ EDDY CURRENT TYPE DIAMETER GAUGE \\ FOR CORROSION MEASUREMENTS
}

by

William B. Doe

\begin{abstract}
An eddy current type instrument, which will detect one ten millionth inch change in the radius of a metal rod, is described. This sensitrvity was required to determine the corrosion rates of corrosion resistant metals without an unduly long corrosion period. Surface oxide films do not interfere with the measurements.
\end{abstract}

\section{INTRODUCTION}

Corrosion rates of metals are frequently determined by weighing a sample before and after a controlled exposure to a corrosive environment. In many cases the weight of the oxide film or corrosion product on the surface of the sample is small compared to the weight of metal removed and may be neglected. In the case of corrosion resistant metals the oxide film cannot be neglected unless the corrosion period is extended to an unreasonable length of time. It is frequently not possible to remove the film chemically without risk of attacking the metal.

This report describes an eddy current type diameter gauge which is not sensitive to non-conducting films on the surface of the sample. The thickness of metal removed in a corrosion test is determined by comparing the diameter of a test rod to a standard rod before and after a period of corrosion. Diameter difference is indicated by alternately inserting test and standard rods into the tank coil of an electrical oscillator and observing the change in tuning capacity required to hold the frequency of oscillation unchanged.

In principle, eddy currents induced in the metal rod change the inductance of the coil and therefore the frequency of oscillation. Since oxide layers or other corrosion products are usually not electrical conductors, the presence of these materials on the surface of the sample do not affect the results. This is an important advantage over the usual weight loss method. 
II. ELECTRICAL DESIGN

\section{A. Frequency Selection}

In general, when using an eddy current method for precise measurements, it is necessary that the electrical conductivity of the sample remain constant. This requires that the temperature be very accurately controlled. Sensitivity of an eddy current instrument to temperature variations of the sample depends upon the operating frequency and the geometry of coil and sample. The theory relating to the testing of a cylindrical sample with a concentric coil has been treated by Hochschild (NYO-3576). Figure 1 is an illustration from this report showing how changes in sample conductivity and diameter affect the electrical characteristics of the test coil.

To measure a diameter change with relative freedom from effects caused by temperature changes, two regions of operation are of interest:

Case 1. Where $\mathrm{Ka}$ is equal to 2.5 , changes in sample conductivity have no effect on the test coil resistance. In other words, changes of Ka are at right angles to the resistance axis. Diameter changes may still be observed as a resistance change.

Case 2. As $\mathrm{Ka}$ approaches infinity changes in sample conductivity produce only small changes in the coil inductance. In other words, the higher the value of $\mathrm{Ka}$, the closer together are these numbers on the chart. Diameter changes may be observed as an inductance change. Case 2 was selected as the more practical area of operation for this type of instrument for several reasons:

(a) Since the frequency is high in Case 2 the eddy currents are limited to a shallow depth in the sample because of "skin effect." Any changes in the interior of the sample do not affect the results.

(b) Case 1 would have required the use of an a-c bridge. This circuit is somewhat awkward to use because two variables must be simultaneously balanced.

(c) A second disadvantage of Case 1 is the low frequency required, which means a large detecting coil resulting in poor coupling to the sample. Good coupling is needed for high sensitivity.

A block diagram of the instrument is shown in Figure 2. One hundred $\mathrm{kc}$ was chosen as the standard frequency since quartz crystals of this frequency are readily avallable. A higher frequency would have given greater freedom from temperature effects; however, this would have made the oscillator design more complicated. 


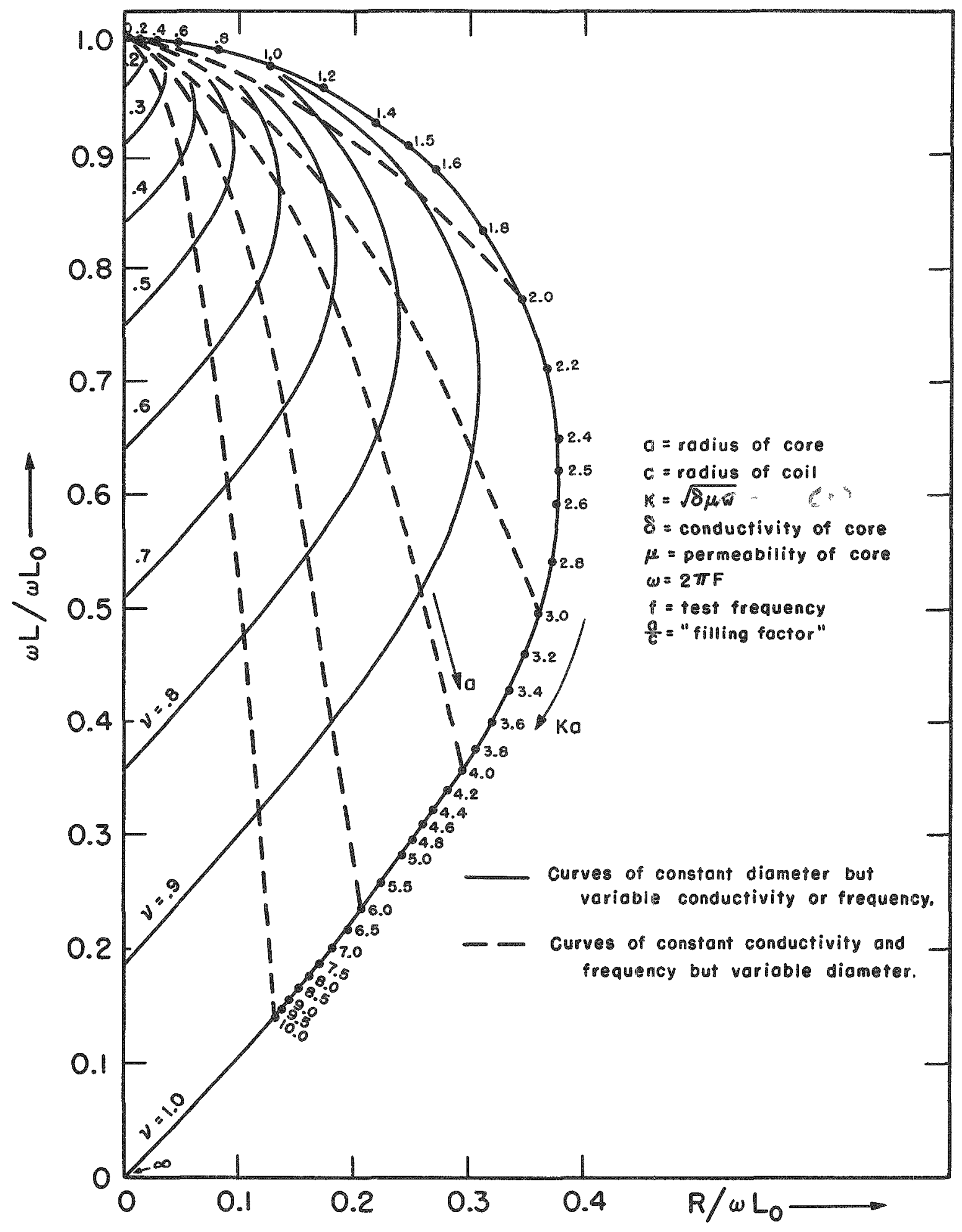

FIGURE

COMPLEX IMPEDANCE OF TEST COIL

FOR VARIATIONS IN THE CORE. 


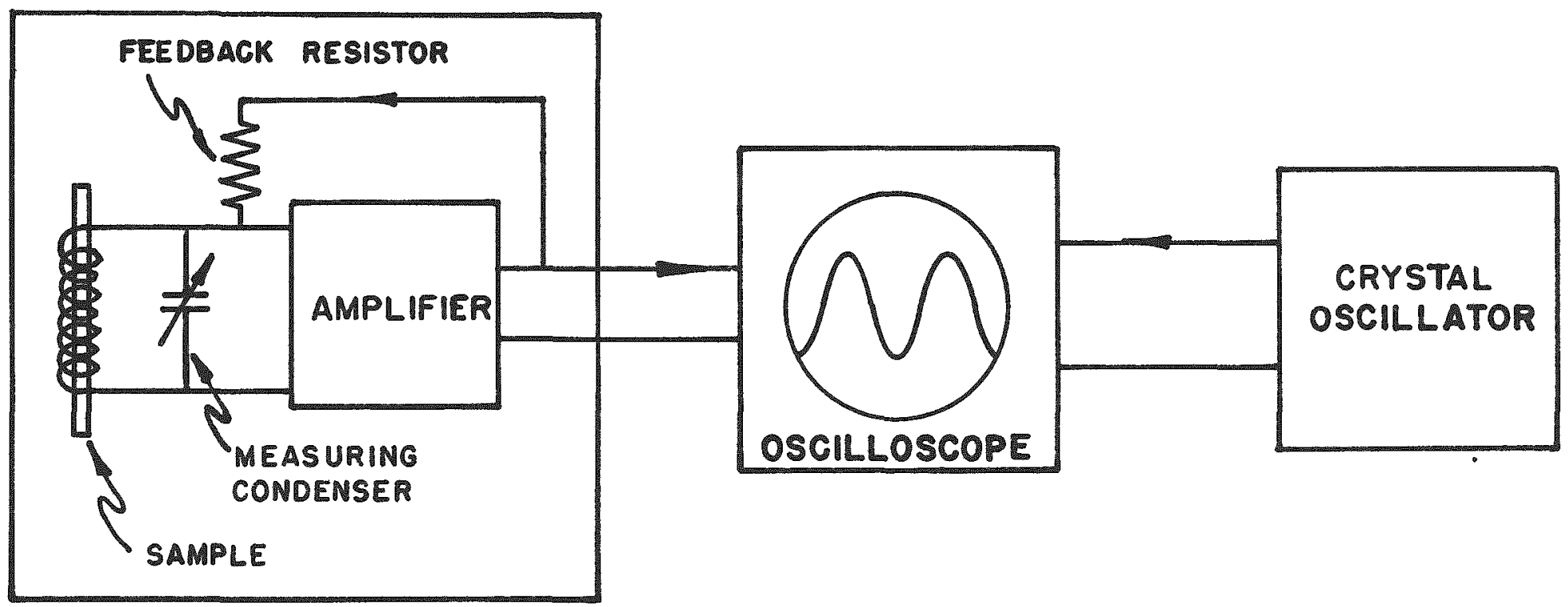

TEST OSCILLATOR

FIG. 2

BLOCK DIAGRAM OF DIAMETER GAGE 
3

In operation, the oscilloscope sweep is synchronized to some subharmonic of the $100 \mathrm{kc}$ oscillator. Output from the test oscillator is fed to the $Y$ axis of the oscilloscope. If the frequency of the test oscillator is above or below $100 \mathrm{kc}$, the pattern on the oscilloscope will move to the right or left. To obtain a reading on a sample, the variable condenser across the detecting coil is adjusted until the pattern remains stationary. The standard is then inserted in the coil and a second reading taken. The difference in the readings is then an indication of the difference in diameter of sample relative to the standard.

\section{B. Test Oscillator}

The $L=C$ oscillator comprises a parallel resonant tank circuit and an amplifier which will feed back energy to the tank circuit to make up for its losses. If the feed back energy is exactly in phase with the tank circuit oscillations the frequency will be the natural resonant frequency of the tank. If there is phase shift in the amplifier, the frequency of oscillation will deviate from the resonant frequency. The lower the ${ }^{b 8} Q^{32}$ of the tank circuit, the greater the frequency deviation for a given phase shift. Thus, for an oscillator to be stable in frequency, either a very high ${ }^{6} \mathrm{Q}^{\text {" }}$ tank, such as a quartz crystal, must be used or variations in amplifier phase shift must be very small.

In the test oscillator under discussion the tank circuit with a metallic sample as its core was necessarily low ${ }^{68} \mathrm{Q}_{0}$ " actually " $\mathrm{Q}^{\prime \prime}=3$ or 4 . Thus, for the high degree of stability required it was necessary to construct an amplifier with negligible variation in phase shift.

The amplifier (Figure $3 a$ ) is a conventional two-stage $R-C$ coupled circuit with cathode follower input and output to isolate the tank circuit. An additional double cathode follower was used to isolate the amplifier output from the oscilloscope in order to prevent locking of the test os cillator frequency with the crystal oscillator.

The amplitude of oscillation was regulated by automatic variation of the grid bias on both amplifying tubes. The bias voltage was obtained by allowing the second amplifying tube to draw a fraction of a microampere of grid current through a 10-megohm resistor. With a properly adjusted feedback resistor, excellent sine wave output was obtained.

To achieve a minimum amount of phase shift in the amplifier, the shift in each of the coupling networks was made as small as possible. Since it is the variation in phase shift, and not its magnitude, that influences frequency stability, the usual practice of using compensation in wide band amplifier design is of no use. 

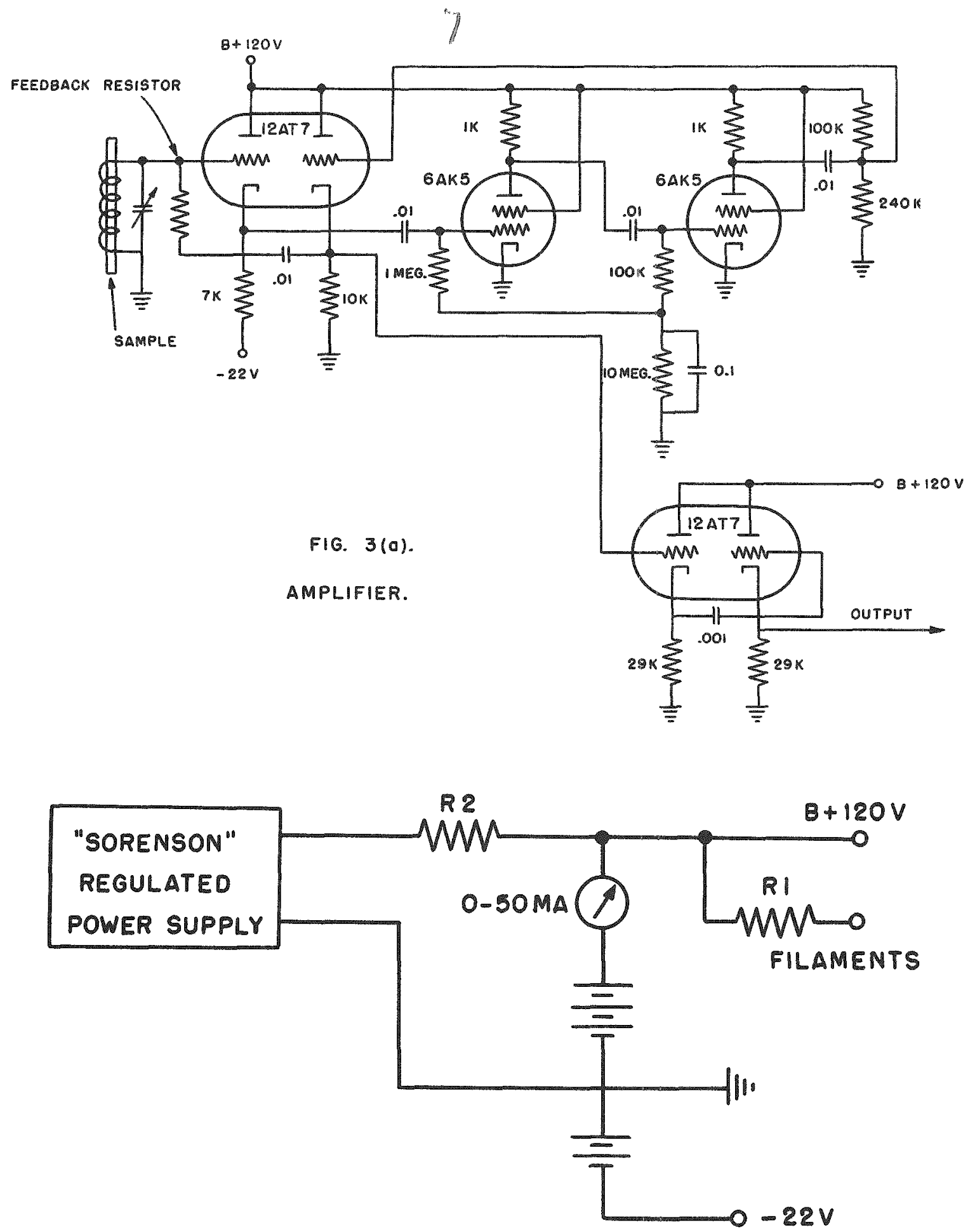

FIG. $3(b)$.

POWER SUPPLY. 
The coupling network causing the greatest shift was the parallel combination of tube resistance and plate load resistor along with the shunting capacitance to ground. The shift from this source was designed to be less than one half degree per tube. For minumum variation in shift, these components should be as constant as possible. The plate load resistor was a ${ }^{86} \mathrm{Koolohm}$ "type NIT 5-watt wirewound. Tube plate resistance was held reasonably constant by accurately regulating the filarnent, plate and screen voltages.

\section{Oscillator Power Supply}

Plate and filament voltages were obtained from the same source with a resistor in series with the filaments.

It was found that voltage variations from a Sorenson "Nobatron" regulator caused apparent variations in sample diameter of a few tenths of a microinch. A stability of about $1 / 100$ volt, or 1 part in 10,000, was obtained by using heavy duty " $B$ "batteries "floating" across the Sorensen output as diagrammed in Figure $3 \mathrm{~b}$.

The output voltage of the Sorensen is adjusted until the milliammeter reads zero, showing that the batteries are floating. With this arrangement greatest stabilization is obtained when the internal resistance of the batteries plus the meter resistance is as low as possible and R2 is as high as possible.

\section{Crystal Oscillator}

The $100 \mathrm{kc}$ oscillator (Figure 4) was very similar to the test oscillator except that, since the ${ }^{"} Q^{3}$ of the crystal is high, a small amount of phase shift could be tolerated. A conventional a-c power supply with a VR tube to regulate the $B+$ voltage was satisfactory. It was found that a $10 \%$ change in line voltage produced less than 1 part in 10,000,000 change in frequency. The $R \cdot F$. choke was necessary to eliminate 60 -cycle ripple in the output.

\section{E. Test Coil}

From Figure 1 it can be seen that for a given diameter change the closer the sample diameter approaches the effective coil diameter the greater will be the percentage change in coil inductance. Theoretically, when the sample is as large as the coil the sensitivity to diameter changes would be infinite. To achieve as high a sensitivity as possible and still maintain a practical clearance between coil and sample, the coil was made self-supporting to avoid the use of a coil form. This was done by machining a rod of fusible alloy and glueing on ferrite type magnetic material (Crolloy) as end pieces for the coil. Fine wire (\#36) was used as the winding to keep 


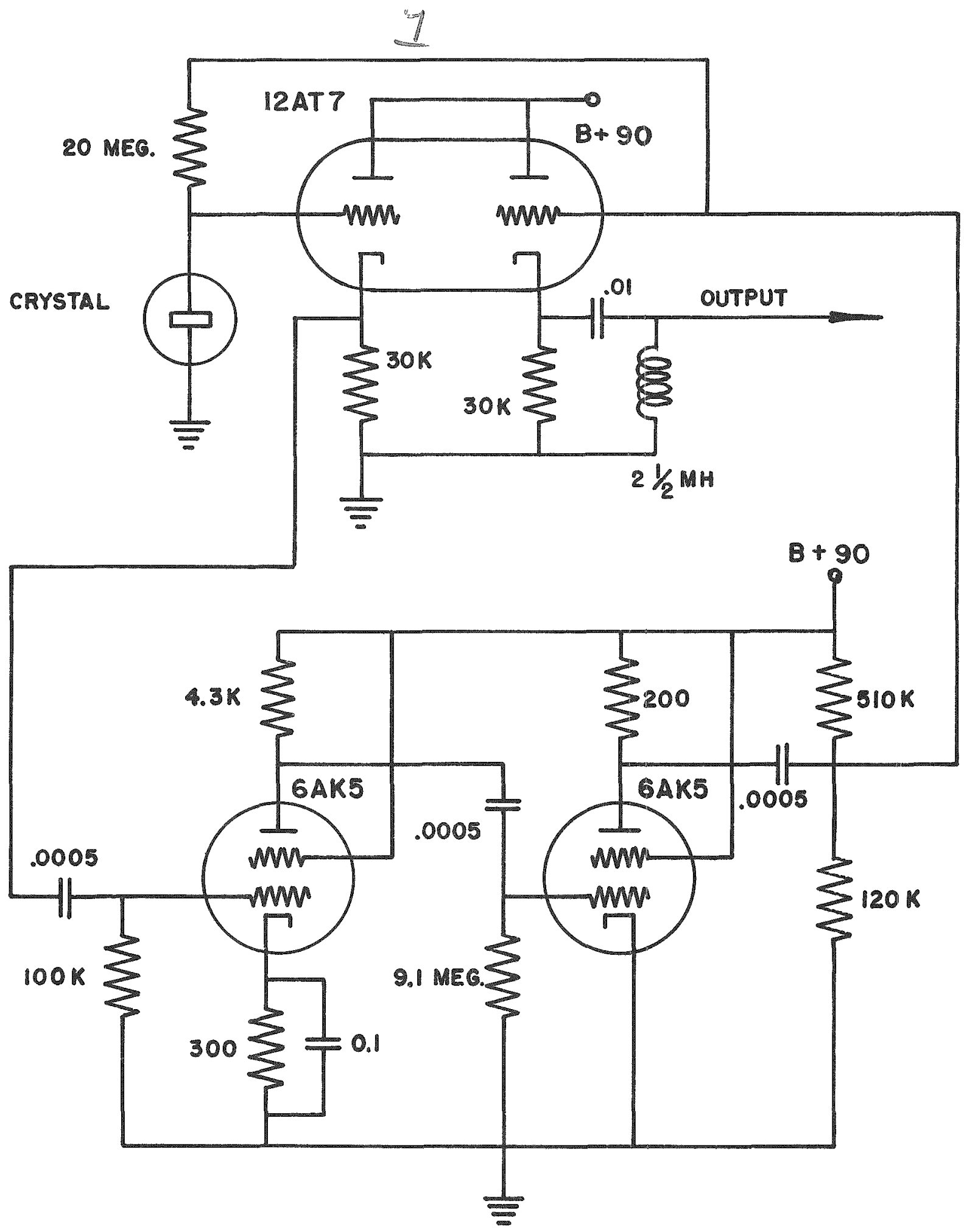

IOO KC OSCILLATOR

FIG. 4 
$\operatorname{los}$

the coil thin and hence close to the sample. Between each layer of winding a room-temperature setting polystyrene (Castolite) was applied and the as sembly allowed to harden overnight. The core was then melted out and Crolloy blocks cemented around the coil to completely enclose it, as shown in Figure 5.

\section{F. Measuring Condenser}

The condensers used to resonate the coil were, first, a fixed main condenser of $1500 \mu \mu \mathrm{f}$. In parallel with this was a $220 \mu \mu \mathrm{f}$ precision variable condenser with its trimmer and padder. The trimmer-padder combination was necessary to convert the straight-line frequency characteristic of the variable condenser to a linear capacity vs rotation characteristic and to reduce the total range to about $7 \mu \mu \mathrm{f}$. The compound dials on the condenser were divided into 5000 divisions so that the capacity could be read directly to $1 / 1000 \mu \mu \mathrm{f}$ or one part in $1,500,000$ of the total capacity. Fixed condensers were all of the silvered mica-high stability type. An adjustable trimmer of about $2 \mu \mu \mathrm{f}$ was also provided to compensate for long term drift in coil inductance so that the standard sample would always read the same on the dial.

\section{TEMPERATURE CONTROL}

There are three types of requirements for temperature control:

\section{(1) Sample-Standard Differential}

Sample and standard temperature must be the same because of physical expansion and because of deeper eddy current penetration if the temperature is increased. It can be calculated that the radius of a $3 / 8$-inch diameter aluminum rod will not change more than $1 / 10$ microinch from physical expansion if the temperature of standard and sample do not differ more than $0.02^{\circ} \mathrm{C}$. To promote temperature equalization the rods are held in the instrument with their ends in contact. It is believed that this is sufficient since heat transfer from the samples to the surrounding air is relatively slow.

\section{(2) Fixed Temperature}

If the readings before and after a period of corrosion are made at different temperatures an error will be introduced unless the thermal expansion coefficient and the temperature coefficient of resistivity of sample and standard are identical. Assuming that the expansion coefficients differ by $1 \%$, it can be calculated that the fixed temperature should not vary more than $2^{\circ} \mathrm{C}$ to have less than $1 / 10$ microinch differential radius change because of physical expansion. To maintain a constant temperature, a resistance winding was applied to four faces of the instrument and the current fed to the winding regulated by a mercurial thermostat set at $28^{\circ} \mathrm{C} \pm 0.01^{\circ} \mathrm{C}$. 


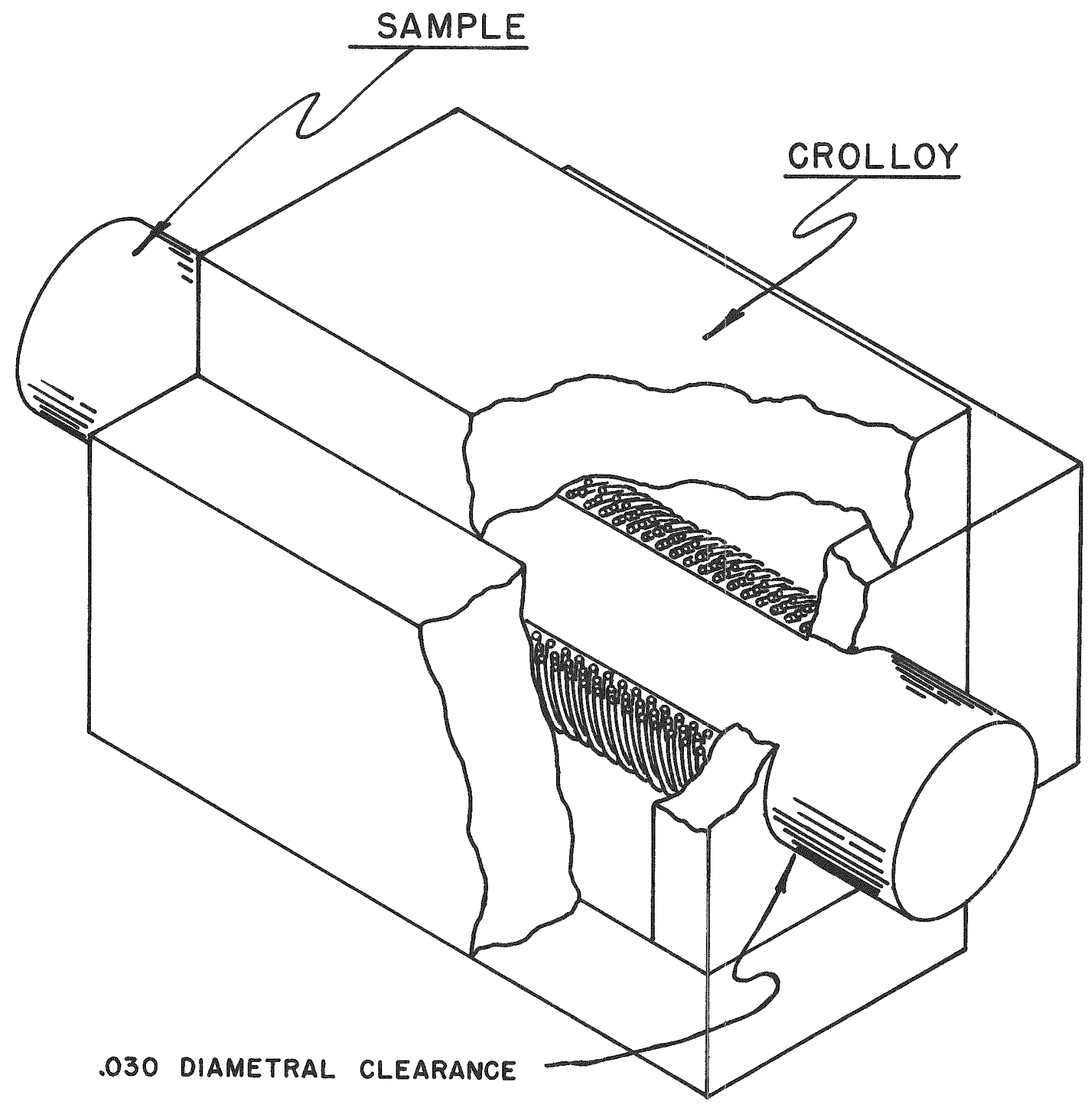

FIG. 5

TEST COIL 


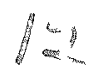

(3) Short Term Temperature Drift

An error will result if the temperature drufts between the time the sample and standard are being read (about 30 seconds). In this case not only are the temperatures of the sample and standard important, but the temperature of the test coil and associated condensers also affect the results. These coefficients can be combined and designated as the short term drift coefficient. Its experimental determination is discussed in Section V. Short term temperature drift was minimized by making the thermal inertia high and the heat losses from the instrument low. The sample chamber was enclosed in a $1 / 4$ minch thick layer of cork to reduce heat loss. The chamber walls were of aluminum, 1/4-inch thick, and the ways and sample carriage were $1 / 2-$ inch thick to provide high heat capacity.

\section{MECHANICAL DESIGN}

The sample and standard were supported on "V" blocks at two points and their ends were in contact to assist heat flow between them. This as sembly was part of a carriage which rode on three steel balls rolling in $\mathrm{V}$ ways with one flat. The carriage could be moved to examine either sample or standard by turning a crank $180^{\circ}$. The ends of the rod.connecting carriage and crank were fastened with ball and socket joints.

To minimize stray capacity changes the leads from coil to variable condenser and amplifier were made as short as possible, the main fixed condenser was mounted directly on the coil.

Figure 6 is a picture of the completed instrument. The oscilloscope, crystal oscillator and power supply are not shown. The measuring condenser housing is at the upper left and the amplifier at the upper right. Between these are the vertical coil-centering screw and the trimming condenser adjustment. The vertical centering screw and a horizontal screw which is not visible center the coil by elastically bending the arm which supports the coil. In addition to the standard rod on the left side of the carriage and the sample on the right, a second sample is in the preheating position just inside the open door. The dial at the lower left operates the crank to traverse the carriage.

\section{PERFORMANCE TESTS}

The instrument was calibrated by treating aluminum rods in a bath of nitric and hydrofluoric acid which will remove the metal in increments without building up an oxide film. The amount removed was calculated from the loss in weight. This gave the calibration as 16 dial divisions per microinch of radius change. 


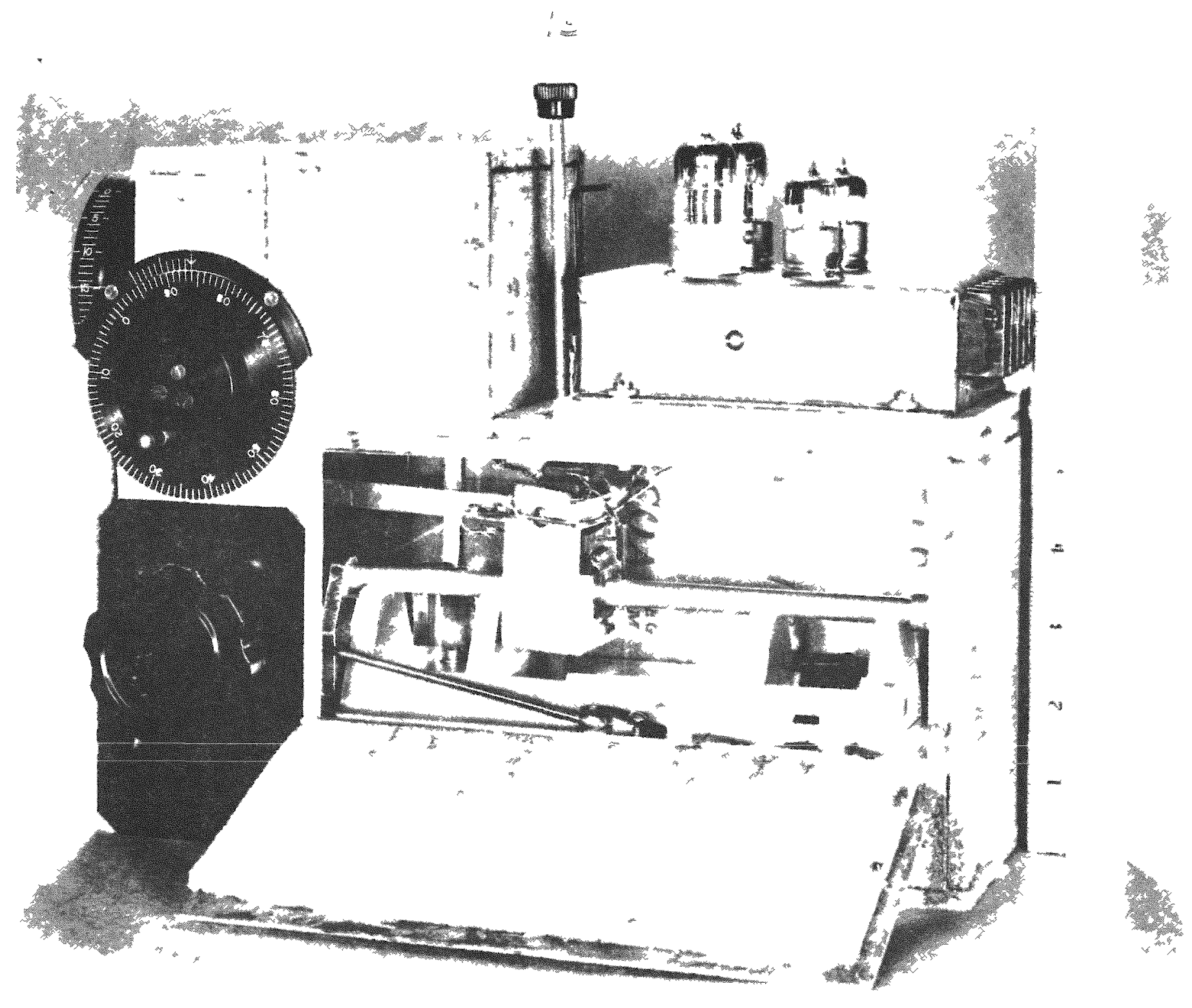

Figure 6

Photograph of Completed Diameter Gauge 
4

To test the stability of the instrument the variable condenser could be rotated and then reset to about $1 / 100$ microinch by observing the oscilloscope pattern.

If the carriage were traversed and returned, the readings were reproducible to $1 / 10$ microinch. If the carriage were traversed, the sample removed and then replaced, and the carriage returned to its original position, the variation was again $1 / 10$ microinch. It appears that irregularity of the carriage motion is the most important factor limiting the sensitivity of the of the instrument. There is room for improvement here since the ways were only roughly machined and precision ball bearings were not used on the traversing dial.

A test was made to determine the effect of improper seating of the sample in the $\mathrm{V}$ blocks. This could be caused by dust particles or formation of a thick oxide film on the sample. Readings were taken on a sample at various adjustments of the vertical coil-centering screw. Degrees of $\mathrm{screw}$ rotation are plotted against instrument reading in Figure 7. These results show that if the coil is properly centered as indicated by the peak of the curve, lifting of the sample by the formation of a surface film 0.002 inches thick would not affect corrosion measurements more than $1 / 10$ microinch.

After placing a sample in the instrument, about 10 minutes were required for temperature equilibrium to be attained. Preheating of the sample shortens this time. Time required to read both sample and standard is approximately 30 seconds.

The short term temperature drift coefficient of the instrument as mentioned in Section III was determined by measuring an aluminum rod at two different fixed temperatures. It was found to be 560 dial divisions, or 35 microinches on the radius per degree $C$, and is of negative sign. Therefore, for an accuracy of $1 / 10$ microinch on the sample radius the temperature must not drift more than $0.003^{\circ} \mathrm{C}$ during the 30 seconds in which the sample and standard are measured.

A negative coefficient could be caused by expansion of the coil, positive coefficient of the tank condenser, or greater penetration of eddy currents. The coil expansion coefficient would be expected to be about the same as the positive sample expansion coefficient which would result in about 1/10 the observed short term coefficient.

Assuming a temperature coefficient of 50 parts per million per ${ }^{\circ} \mathrm{C}$ for the silver mica tank condenser, the effect would also be about $1 / 10$ the observed value. From these considerations it is concluded that even though the frequency of operation of the instrument is $100 \mathrm{kc}$, the variation in depth of eddy current penetration is the major factor controlling the sensitivity of the unit to temperature changes. 


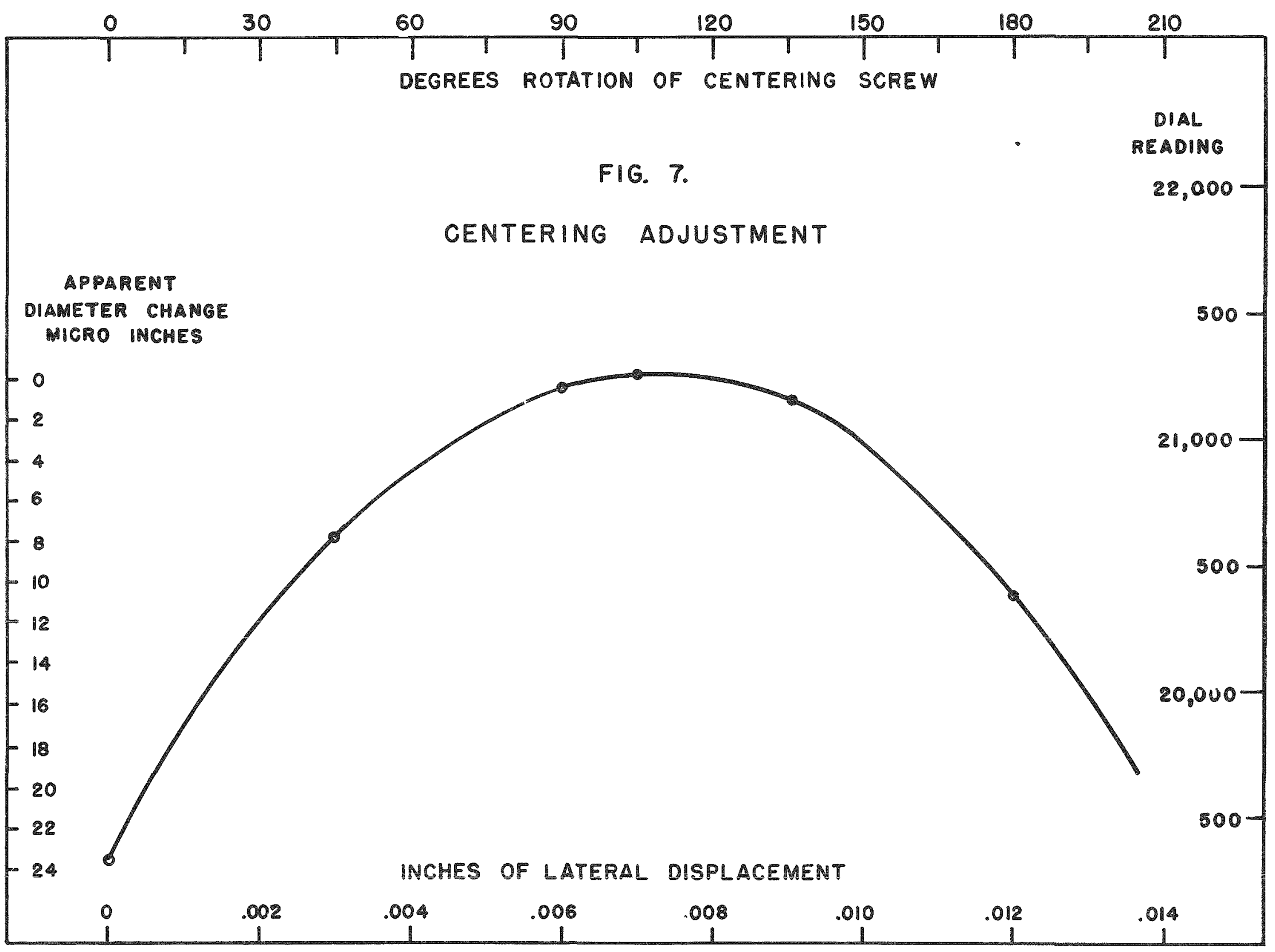




\section{CONCLUSION}

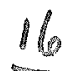

The achievement of a usable sensitivity of one ten millionth radius inch change in a sample was due in a large measure to the minimization of the principal sources of eror in the following manner:

1. Since the method is a rapid comparison of the properties of two rods, long term changes in the electrical components do not affect the results.

2. The effect of rapid changes in the amplifier components has been minimized by making the phase shift small so that the variation in phase shift while a measurement is in progress will be even smaller.

3. The use of a relatively high frequency minimized the effect of sample resistivity changes caused by temperature differences.

4. The use of a totally self-enclosed magnetic circuit eliminated flux leakage problems.

5. The use of cylindrical sample geometry which is naturally rigid and which can be generated to high accuracy by machining reduced sample mislocation problems. Measurement errors due to longitudinal mislocation of the sample approach zero as the sample taper approaches zero: also, warping of a cylindrical sample would be expected to be less than that of a ribbon or disc.

6. Instrument response versus lateral displacement of the sample goes through a maximum when the sample is in the center of the coil. By using the instrument as its own centering detector, the sample may be accurately centered where a small lateral mislocation will cause a minimum amount of exror.

\section{ACKNOWLEDGEMENTS}

The author wishes to acknowledge the advice and helpful suggestions of I.E.Draley and W.E.Ruther of the Metallurgy Division, and Professor D. L. Waidelich of the University of Missouri Faculty。 